\title{
The Efficacy Of Business Ethics Courses When Coupled With A Personal Belief System
}

Brian D. Neureuther (E-mail: sdbrian@isugw.indstate.edu), Indiana State University Philip Swicegood (E-mail: pswicedgood@gardner-webb.edu), Gardner-Webb University Philip Williams (E-mail: Williams@Methodist.edu), Methodist College

\begin{abstract}
Business educators are being challenged on an increasing basis to reassess the ethical awareness of their students and the effectiveness of their ethics education. In this paper we test a traditional approach to ethics exposure in business law classes, which is the primary venue for teaching ethics in many business curriculums. We find that ethics exposure in the traditional business law course using popular textbooks does not influence the ethical sensitivity of students. We also document that ethical sensitivity of students breaks down at several levels. Business students have different personal standards as compared to acceptable corporate standards of ethics.
\end{abstract}

\section{Introduction}

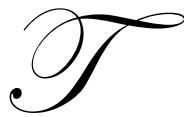

he need for business students - as our future business leaders - to develop ethical sensitivity and standards is self-evident. Understanding if and when a person's ethical framework develops is one of the key areas of business ethics research. In this paper we examine experiences both inside and outside of the classroom that may have impact on a person's ethical formation. We also examine the subjectivity of people's ethical frameworks.

The effectiveness of business ethics training in various business courses has been met with mixed results. Some studies conclude that students' degree of ethical sensitivity show marked improvements (Carlson and Burke, 1998), moderate improvements (Glenn, 1992), and no improvements (Wynd and Mager, 1989, and DeMoss and McCann, 1997). Business school graduates generally rank schooling very low on influencing their ethical sensitivity (Arlow and Ulrich, 1985). Many business schools rely on business law courses to be the primary arena for challenging students to think critically about ethical issues and decision-making. These courses use textbooks that include chapters ostensibly designed to acquaint students with ethical considerations surrounding the legal topics being discussed. An underlying assumption of this approach is that students would be able to identify the existence of an ethical problem - if not prior to taking the course, then certainly after taking the course in question. Here we test the effectiveness of this common approach to ethical pedagogy.

Numerous studies in the past have explored ethical sensitivity with regards to demographic factors, cognitive-personality factors, and work-organizational factors (Collins, 2000). In this paper we examine the three personal traits most commonly debated: work experience, gender, and religious commitment, with particular interest on the latter.

\section{Research Questions And Hypothesis}

In this study we examined the extent to which the mere exposure of students to traditional business law coursework covering ethical issues would be sufficient to sensitize them to the existence of an ethical dilemma when one is actually encountered. Given that the textbook chapters appeared to be designed, in part, to accomplish exactly that goal, our primary research hypothesis followed naturally: 
H1: University students exposed to traditional business law coursework covering ethical issues will be equally sensitive to the existence of ethical dilemmas compared to students who have not been exposed to such material.

Given the nature of the survey questionnaire, secondary hypotheses became apparent. These secondary hypotheses may be described as follows:

H2(a): A person's religious commitment has no effect on one's degree of ethical sensitivity.

H2(b): A person's gender has no effect on one's degree of ethical sensitivity.

H2(c): A person's work experience has no effect on one's degree of ethical sensitivity.

\section{Research Methodology}

The study examined the primary hypothesis by comparing the survey responses of students to a variety of ethical situations presented in identical fashion at the beginning and at the end of a semester (henceforth referred to as pre-course surveys and post-course surveys, respectively) of business coursework. In the survey (see Appendix), 200 university students taking business law classes were asked to read and assess six scenarios involving ethical dilemmas that might be encountered by management employees in the real world. Using a five point Likert scale, students were asked to rate (1) the extent to which each scenario would present ethical concerns for him or her personally, and (2) the extent to which each scenario should, in his or her opinion, would raise ethical concerns for the hypothetical organization in question. In addition, students were asked to categorize the extent of their previous work experience, the role of religion in their lives, and their gender.

\section{Results - Hypothesis 1}

For clarity, the first hypotheses is restated: University students exposed to traditional business law coursework covering ethical issues will be equally sensitive to the existence of ethical dilemmas compared to students who have not been exposed to such material.

The statistical significance of differences arising under the primary hypothesis was determined by applying a t-test procedure to compare student survey answers given on scenarios 1 through 12 of the survey at the beginning of the semester with those answers given at the end of the semester.

An analysis of their results concludes there is no significant difference in the student's ethical perception by taking the ethics course (using 10\% significance level). In other words, the ethics course does not change one's ethical perceptions. This conclusion is very statistically solid because of the extremely high p-value (.4473).

\begin{tabular}{|l|c|c|c|}
\hline \multicolumn{1}{|c|}{ Survey } & Means & T-Statistic & P-Value \\
\hline Pre-test & 23.818 & & \\
\hline Post-test & 24.188 & & \\
\hline Statistical T-test & & $\mathbf{. 7 6}$ & $\mathbf{. 4 4 7 3}$ \\
\hline
\end{tabular}

\section{Results - Hypothesis 2a, 2b, 2c}

For clarity, the second hypotheses are restated: Hypothesis 2(a). A person's religious commitment has no effect on one's degree of ethical sensitivity; Hypothesis 2(b). A person's gender has no effect on one's degree of ethical sensitivity; Hypothesis 2(c). A person's work experience has no effect on one's degree of ethical sensitivity.

For purposes of answering the second hypotheses, survey data were analyzed using a multiple regression model in which the dependant variable was the student's mean average score on the first twelve scenario questions. Independent variables included students' self-reported reported work experience, extent of religious faith, and gender. 
The pre-course survey indicates that experience, religion, and gender all contribute significantly to a student's ethical sensitivity (using a 10\% significance level). The most influential variable on ethical sensitivity was gender, followed by experience and then by religion.

Further, we can infer that:

- $\quad$ A female student is more ethically sensitive than a male.

- $\quad$ The more work experience someone has, the more ethical they become.

- The more involved someone is in their religion, the more ethically sensitive they become.

The post-course survey indicates that experience and religion contribute significantly to a student's ethical sensitivity, but gender no longer does. I would infer that by taking the ethics course, the influence of the student's gender was dampened by the course content in terms of their ethical sensitivity. In other words, females are no longer more ethical than males.

Further, we can infer that:

- $\quad$ The more work experience someone has, the more ethical they become.

- The more involved someone is in their religion, the more ethically sensitive they become.

It would also appear that: Experience became a much more significant factor in ethical sensitivity after taking the course, i.e., the course has seemed to re-emphasize ethical behavior for those with work experience. The same cannot be said of religion.

\begin{tabular}{|c|c|c|c|}
\hline Survey & $\begin{array}{c}\text { Work } \\
\text { Experience }\end{array}$ & $\begin{array}{c}\text { Religious } \\
\text { Commitment }\end{array}$ & Gender \\
\hline Pre-test & & & \\
\hline F-statistic & 6.70 & 5.11 & 7.29 \\
\hline P-value & .0103 & .0248 & .0075 \\
\hline Post-test mean & & & \\
\hline F-statistic & 15.5 & 5.13 & 1.14 \\
\hline P-value & .0001 & .0252 & .2883 \\
\hline
\end{tabular}

\section{Conclusion}

Future research will continue to examine further hypothesis, such as whether or not there is a difference between personal ethical standards and corporate ethical standards. We would also like to examine this difference with respect to gender, religious involvement, and work experience. Also, we would like to examine the hypothesis that there is a difference in ethical standard for doing business domestically versus internationally. We would also like to examine this difference with respect to gender, religious involvement, and work experience. Finally, we would like to examine whether or not ethical standards are subjective to the ends justifying the means. We would also like to examine this difference with respect to gender, religious involvement, and work experience.

\section{References}

1. Arlow, P. and T. Ulrich: 1985: "Business Ethics and Business School Graduates: A Longitudinal Study," Akron Business and Economic Review 16, 13-17.

2. Carleson, P. and F. Burke, "Lessons Learned from Ethics in the Classroom: Exploring Student Growth in Flexibility, Complexity, and Comprehension," Journal of Business Ethics 17, 1179-1187

3. Colins, Denis: 2000, "The Quest to Improve the Human Condition," Journal of Business Ethics 26, 1-73.

4. Demoss and McCann: 1997. 
5. Glenn, J.: 1992, "Can a Business and Society Course Affect the Ethical Judgment of Future Managers?" Journal of Business Ethics 11, 217-223.

6. Wynd, W. and J. Mager: 1989, "The Business and Society Course: Does it Change Students Attitudes?" Journal of Business Ethics 8, 487-491.

\section{Appendix A Ethics Questionnaire}

Please take a few minutes to complete this ethics questionnaire as completely as possible. We are seeking to better understand ethical attitudes and opinions of our students. All responses are confidential. Please do not provide your name or other unique information. Thank you for your participation.

Betty Buyer is responsible for purchasing all merchandise for XYZ Department Store. XYZ's advertised mission is to buy the highest quality merchandise at the lowest possible price so that it can pass these savings along to consumers. In order to get the lowest possible price from the RST Textile Plant, Betty takes their marketing vice president to dinner and secretly offers him a "personal appreciation gift" of \$1,000 cash if he can arrange a special $50 \%$ discount on all RST products sold to XYZ.

1. From the standpoint of your own ethical standards, how would you characterize Betty's actions?
a. I would consider them to be highly unethical
b. $\quad$ I would consider them to be somewhat more unethical than ethical
c. I would consider them to be ethically neutral
d. I would consider them to be somewhat more ethical than unethical
e. I would consider them to be highly ethical

2. From the standpoint of XYZ Department Store's top management, which of the following statements is most accurate?
a. $\quad$ XYZ's top management should consider Betty's actions to be highly unethical
b. XYZ's top management should consider Betty's actions to be more unethical than ethical
c. $\quad$ XYZ's top management should consider Betty's actions to be ethically neutral
d. $\quad X Y Z$ 's top management should consider Betty's actions to be more ethical than unethical
e. $\quad X Y Z$ 's top management should consider Betty's actions to be highly ethical

When Betty is unable to find a decent price for clothing in the United States, she travels to the Kingdom of Elbonia, which is known for the fine quality of its textiles. Betty learns that "personal appreciation gifts" are customary in Elbonia. In order to get the lowest possible price from the Elbonian National Textile Plant, Betty takes their marketing vice president to dinner and secretly offers him a "personal appreciation gift" of \$1,000 cash if he can arrange a special $50 \%$ discount on all Elbonian textiles sold to XYZ Department Store.

3. From the standpoint of your own ethical standards, how would you characterize Betty's actions?
a. I would consider them to be highly unethical
b. I would consider them to be somewhat more unethical than ethical
c. I would consider them to be ethically neutral
d. I would consider them to be somewhat more ethical than unethical
e. I would consider them to be highly ethical

4. From the standpoint of XYZ Department Store's top management, which of the following statements is most accurate?
a. $\quad$ XYZ's top management should consider Betty's actions to be highly unethical
b. $\quad$ XYZ's top management should consider Betty's actions to be more unethical than ethical
c. $\quad$ XYZ's top management should consider Betty's actions to be ethically neutral
d. XYZ's top management should consider Betty's actions to be more ethical than unethical
e. XYZ's top management should consider Betty's actions to be highly ethical 
Joe is the Director of Marketing for XYZ Department Store. He has just learned that his computer is down and will not be repaired for at least two weeks. Joe sees an offer for a new computer with a 30-day inspection period and money-back guarantee. He has no intention of buying the computer, but decides to take the computer back to his office and use it to create advertisements and marketing flyers for the next 29 days. He then returns the computer on the $30^{\text {th }}$ day and receives a full refund of the purchase price.

5. $\quad$ From the standpoint of your own ethical standards, how would you characterize Joe's actions?
a. I would consider them to be highly unethical
b. I would consider them to be somewhat more unethical than ethical
c. I would consider them to be ethically neutral
d. I would consider them to be somewhat more ethical than unethical
e. I would consider them to be highly ethical

6. From the standpoint of XYZ Department Store's top management, which of the following statements is most accurate?
a. $\quad$ XYZ's top management should consider Joe's actions to be highly unethical
b. $\quad$ XYZ's top management should consider Joe's actions to be more unethical than ethical
c. $\quad$ XYZ's top management should consider Joe's actions to be ethically neutral
d. $\quad X Y Z$ 's top management should consider Joe's actions to be more ethical than unethical
e. $\quad$ XYZ's top management should consider Joe's actions to be highly ethical

Pat, the plant manager of RST's North Carolina textile plant, decides to lay off all 500 workers at the factory and open a new factory in the Kingdom of Elbonia, where the typical factory worker will be happy with a wage of less than one dollar per hour. Pat tells RST's top management that RST will save over \$2 million in wage expenses annually by moving the factory to Elbonia.

7. From the standpoint of your own ethical standards, how would you characterize Pat's actions?
a. I would consider them to be highly unethical
b. I would consider them to be somewhat more unethical than ethical
c. I would consider them to be ethically neutral
d. I would consider them to be somewhat more ethical than unethical
e. I would consider them to be highly ethical

8. From the standpoint of RST's top management, which of the following statements is most accurate?
a. RST's top management should consider Pat's actions to be highly unethical
b. RST's top management should consider Pat's actions to be more unethical than ethical
c. RST's top management should consider Pat's actions to be ethically neutral
d. RST's top management should consider Pat's actions to be more ethical than unethical
e. RST's top management should consider Pat's actions to be highly ethical

Pete works for MNO Investments as a financial manager. He persuades an elderly couple to sell their entire portfolio of treasury bonds - worth $\$ 200,000$ - and buy shares of speculative stock options. MNO will earn a fee of $\$ 5,000$ for the transaction, of which $\$ 2,000$ will go to Pete as a sales commission.

9. From the standpoint of your own ethical standards, how would you characterize Pete's actions?
a. I would consider them to be highly unethical
b. I would consider them to be somewhat more unethical than ethical
c. I would consider them to be ethically neutral
d. I would consider them to be somewhat more ethical than unethical
e. I would consider them to be highly ethical 
10. From the standpoint of MNO's top management, which of the following statements is most accurate?

a. MNO's top management should consider Pete's actions to be highly unethical

b. $\quad$ MNO's top management should consider Pete's actions to be more unethical than ethical

c. MNO's top management should consider Pete's actions to be ethically neutral

d. MNO's top management should consider Pete's actions to be more ethical than unethical

e. MNO's top management should consider Pete's actions to be highly ethical

Suppose that the stock market rises rapidly over the next six months and the elderly couple's speculative investment is now worth over $\$ 300,000$, which is quite a bit more than their treasury bonds would have earned.

11. From the standpoint of your own ethical standards and taking account of the stock market's subsequent activity, how would you now characterize Pete's actions?
a. I would consider them to be highly unethical
b. I would consider them to be somewhat more unethical than ethical
c. I would consider them to be ethically neutral
d. I would consider them to be somewhat more ethical than unethical
e. I would consider them to be highly ethical

12. From the standpoint of MNO's top management and taking account of the stock market's subsequent activity, which of the following statements is most accurate?
a. MNO's top management should consider Pete's actions to be highly unethical
b. MNO's top management should consider Pete's actions to be more unethical than ethical
c. MNO's top management should consider Pete's actions to be ethically neutral
d. MNO's top management should consider Pete's actions to be more ethical than unethical
e. MNO's top management should consider Pete's actions to be highly ethical

\section{Personal profile questions}

13. Which best describes the extent of your full-time professional work experience?
a. None
b. $\quad 1-3$ years
c. 3-10 years
d. More than 10 years

14. Which best describes your religious involvement?
a. $\quad$ Religious faith plays no role in my daily life.
b. $\quad$ Religious faith plays an occasional role in my daily life.
c. Religious faith plays a significant role in my daily life.

15. __ Male _ Female 